\title{
ANALYTICAL PULL-OUT MODEL FOR EXTENSIBLE SOIL-REINFORCEMENTS
}

\author{
Netra GURUNG ${ }^{1}$ and Yushiro IWAO ${ }^{2}$ \\ ${ }^{1}$ Member of JSCE, Doctoral Student, Department of Civil Engineering, Saga University (Saga 840-8502, Japan) \\ ${ }^{2}$ Member of JSCE, Dr. Eng., Professor, Department of Civil Engineering, Saga University (Saga 840-8502, Japan)
}

\begin{abstract}
A pullout test model is proposed using hyperbolic relation for highly extensible soil-reinforcement. The non-linear equation for interface pullout mechanism was non-dimensionalised, expressed in finite difference form and solved numerically using the Guass-Siedel technique. A parametric study was carried out for various ranges of relative stiffness and relative bond resistance. The normalised loaddisplacement relations and the variations of pullout force and reinforcement displacements with distance, are presented. The interface pullout response of the model is compared with the available experimental pullout test results for geotextile, polymer and nylon geosynthetic reinforcements.
\end{abstract}

Key Words: extensible soil-reinforcement, geosynthetic, interface mechanism, numerical analysis, pullout test

\section{INTRODUCTION}

The pullout test for soil inclusions is used for checking the strength, integrity and effectiveness of the soil-reinforcement system. For strength or stability or differential settlements, the geosynthetics has become popular in civil and geo-environmental engineering. Its usage has a unique advantage over other methods due to their lighter, stronger and stiffer characteristics. Field and laboratory pullout tests are widely used to interpret the interaction mechanisms between reinforcement and soil. Yang ${ }^{17)}$ and Schlosser and Long ${ }^{13)}$ proposed anisotropic cohesion and enhanced confining pressure concepts respectively for increased strength of reinforced soil. Hausmann ${ }^{6}$ pointed absence of anisotropic cohesion at low confining stresses but postulated pullout failure by slippage or loss of adherence as a mechanism. McGown et al. ${ }^{10)}$ distinguished the different load-deformation responses in terms of the failure strain levels for (Fig. 1) extensible and inextensible reinforcements.

Basic design criteria for reinforced earth structures demands checking for external and internal stability (Mitchell and Villet ${ }^{11)}$; Christopher et al. ${ }^{4)}$ ). Jewell and Wroth ${ }^{7)}$ established that reinforcement in the direction of tensile strain strengthens the soil. Schlosser and Buhan ${ }^{14)}$ simplified the soilreinforcement interaction mechanisms to either direct shear or pullout by neglecting bending resistance of reinforcement that significantly simplified the analysis mechanisms. The concept of different

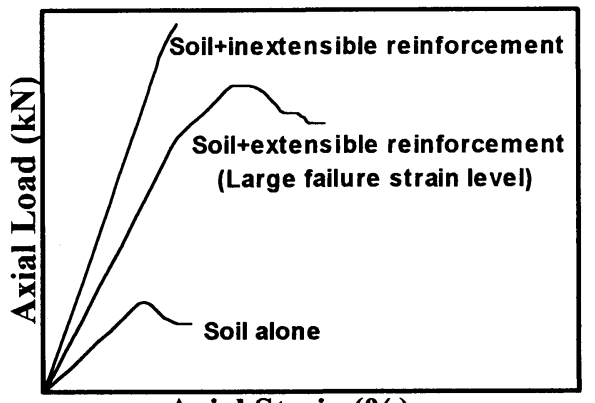

Axial Strain (\%)

Fig.1 Load strain characteristics of reinforcements (McGown et al. ${ }^{10)}$ )

degrees of mobilisation of bearing resistance along the length of reinforcement owes to Jewell ${ }^{7)}$ who empirically suggested the use of the critical state angle of friction of soil instead of peak to define the soil reinforcement interface mechanism.

To understand and evaluate the mechanism of interaction and its parameters in reinforced soil, various researchers popularly used pullout tests. The effect of normal pressure and drainage is to increase the pullout resistance (Pradhan et al. ${ }^{12)}$ ). Based on field pullout tests on geosynthetics, Konami et al. ${ }^{8)}$ presented an elastic model for polymer strips that explains the initial linear response. Abramento and Whittle ${ }^{1)}$ proposed approximation for bi-axial stresses for the analysis of planar reinforcement in 


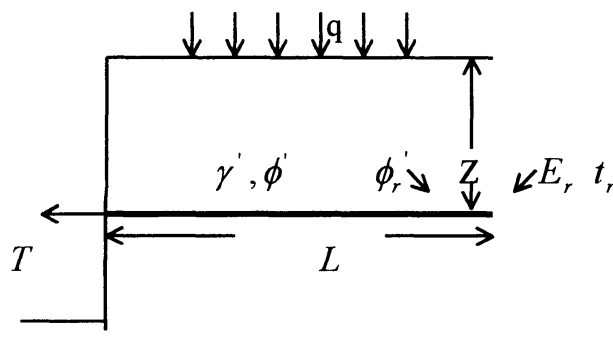

(a) Soil-reinforcement system

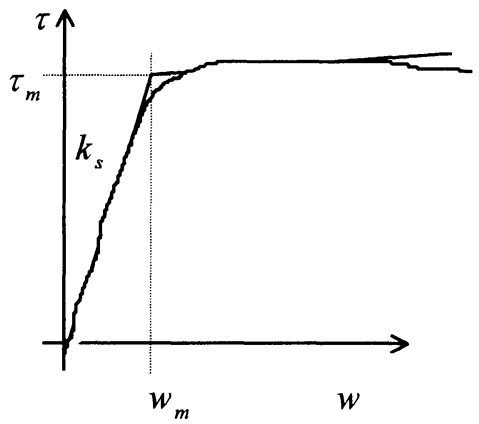

(c) Stress-displacement curve

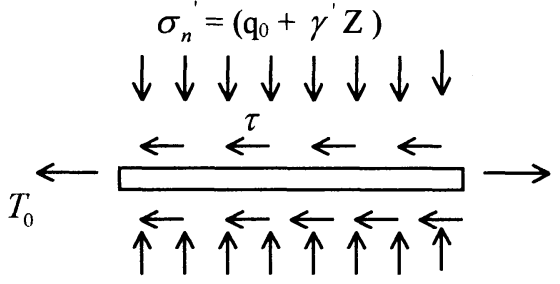

(b) Forces on reinforcement

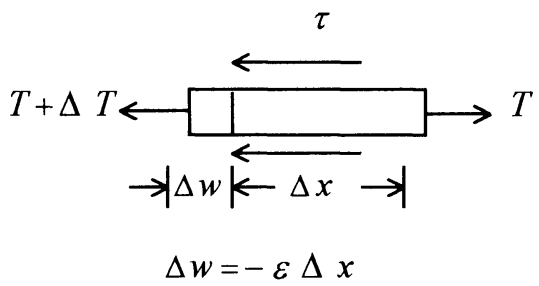

(d) Free body of reinforcement element

Fig. 2 Conceptual diagram on pullout tests for soil-reinforcement

pullout based on the shear lag theory. Segrestin and Bastick ${ }^{15)}$ showed non-linear and linear response patterns for extensible and inextensible reinforcements respectively. Sobhi and $\mathrm{Wu}^{16)}$ have contributed an interface model based on rigid-plastic shear stress mobilisation for extensible reinforcement. But the pullout test results in terms of variation of mobilised tension, pre-yield and postyield behaviour, effective and extended lengths of the reinforcement etc. are fairly predicted by most of the above theories.

This is due to the fact of the variation of mobilised shear stresses along the interface length of the soil-reinforcement in pullout tests, which is nonlinear for extensible reinforcements. The interface pullout formulation for bi-linear model was theoretically derived in the previous paper by Madhav et al. ${ }^{9)}$ taking into account shear stress variations and extensible nature of modern geosynthetics. The elasto-plastic relation of Gurung and Iwao ${ }^{5)}$ may be extended by incorporating a hyperbolic shear stress-displacement relation along the interface for the prediction of non-linear responses during pullout test for highly extensible geosynthetics. A non-linear elastic model, such as this newly proposed hyperbolic relation could even realistically simplify the mobilisation of shear stress in pullouts than that of the bi-linear approximations.
The proposed hyperbolic relation offers simplicity, faster convergence and is closer to the reality in terms of mobilised shear stress and nonlinear strains. The proposed model considers highly extensible planar soil-reinforcements and incorporates a hyperbolic shear stress-displacement relationship for the interface response, during the pullout test. The non-linear governing equation relating the applied pullout force, displacements and distance are normalised and solved numerically to obtain the pullout force displacements relationships, and the variations of pullout force and displacements with distance. The predictions are compared with results of laboratory and field pullout tests on geotextiles and nylon as well as polymer strip geosynthetics. The model will be useful to simulate pullout responses and to understand the degree of interface interactions.

\section{MODEL FORMULATION}

Figure 2 (a) depicts a pullout test on geosynthetic sheet reinforcement. The detail of general formulation for interface pullout was derived in the previous paper on theoretical pullout model for extensible reinforcements by Madhav et al. ${ }^{9)}$. A brief summary is hereby presented and it is modified for 
the proposed hyperbolic case as follows. Consider the reinforcement is of length, $L$ and $E_{r}$ and $t_{r}$ are its elastic modulus and thickness respectively. Let's assume the tensile strength $T_{y}$ of the reinforcement is significantly high compared to the pullout force so that reinforcement breakage is not possible. The pullout force, $T_{0}$, is applied or measured slightly away from the face so that the end effects (Jewell and Wroth ${ }^{7)}$ ) are avoided. The applied pullout force, $T_{0}$, mobilises interface shear stress, $\tau$, along the length of reinforcement. The interface shear stress, $\tau$, are governed by the interface response shown in Fig. 2(c).

From a typical direct shear test, it can be observed that the interface shear stress increases with relative displacement, $w$, and reaches asymptotically the maximum shear resistance, $\tau_{m}$. The strain softening responses as observed in some cases, is not included in this study, but may also be formulated in similar manner. For simplicity, the actual $\tau$ versus $\mathrm{w}$ curve is simplified by hyperbolic response curve, as

$$
\tau=\frac{w}{a+b w}
$$

where $a=1 / k_{s}$ and $b=1 / \tau_{m} \& \tau_{m}$, is limited to

$$
\tau_{m}=\sigma_{n}{ }^{\prime} \tan \phi_{r}^{\prime}=\left(\mathrm{q}_{0}+\gamma^{\prime} \mathrm{Z}\right) \tan \phi_{r}{ }^{\prime}
$$

and $\sigma_{n}{ }^{\prime}=\left(\mathrm{q}_{0}+\gamma^{\prime} \mathrm{Z}\right)$ is the effective normal stress on the interfaces, $\mathrm{q}_{0}$ - the surcharge stress, $\gamma^{\prime}$ effective unit weight of the fill, $Z$ - the depth of the reinforcement and $\phi_{r}^{\prime}$ - the effective interface friction angle. In this study, the reinforcement is considered to be highly extensible as is likely in case of some geosynthetics and geomembranes. Therefore, considering (Fig. 2d) the extended length of a small differential element of length, $\Delta x$, and of unit width of the reinforcement, the equilibrium of horizontal forces is satisfied by

$$
(T+\Delta T)-T+2 \tau(\Delta x+\Delta w)=0
$$

where $T$ and $(T+\Delta T)$ are the pullout forces in the reinforcement on the right and left ends, $\tau$ - the mobilised bond resistance, and $\Delta w$ - the elongation of the element, $\Delta x$. The elongation, $\Delta w$, is related to the strain, $\varepsilon$, as

$$
\Delta w=-\varepsilon \Delta x
$$

while the strain, $\varepsilon$, is related to the tensile force, $T$, as

$$
\varepsilon=T / E_{r} t_{r}
$$

Eq. (3) can be simplified as

$$
\frac{d T}{d x}+2 \tau(1+\varepsilon)=0
$$

Noting that for the $\mathrm{x}$ - axis is positive to the right, i.e. $\varepsilon=-\frac{d w}{d x}$, Eq. (5) and (6) are combined to give

$$
-E_{r} t_{r} \frac{d^{2} w}{d x^{2}}+2 \tau\left(1-\frac{d w}{d x}\right)=0
$$

Equation (7) is the basic equation governing the response of a highly extensible reinforcement. The interface shear stress given by Eq. (1) is coupled with Eq. (7) to arrive at

$$
E_{r} t_{r} \frac{d^{2} w}{d x^{2}}+2 \frac{k_{s} w}{\left(1+\frac{k_{s}}{\tau_{m}} w\right)}\left(\frac{d w}{d x}-1\right)=0
$$

Equation (8) is non-dimensionalised by $W=$ $w / w_{m}, X=x / L$, and simplified to get

$$
\frac{d^{2} W}{d X^{2}}+\frac{\alpha W}{(1+W)}\left\{\beta \frac{d W}{d X}-1\right\}=0
$$

where $\alpha=\frac{2 k_{s} L^{2}}{E_{r} t_{r}}$ and $\beta=w_{m} / L=\tau_{m} /\left(k_{\mathrm{s}} L\right)$

The boundary conditions become

at $X=0, \varepsilon=-\frac{d w}{d x}=\frac{T_{0}}{E_{r} t_{r}}$

$$
\text { or } \quad \frac{d W}{d X}=-\alpha T^{*}
$$

where $T^{*}=T_{0} / T_{m}$ and $T_{m}=2 \tau_{m} L \quad$ - the maximum pullout force.

and

$$
X=1, \varepsilon=0
$$

Equation (9) is non-linear differential equations, which cannot be solved analytically.

Discretising (Fig. 3) the reinforcement into " $n$ " elements each of length $\Delta L=L / n$ or $\Delta X=1 / n$, and expressing the derivatives in finite difference form, Eq.s (9) is rewritten for $\mathrm{i}^{\text {th }}$ node as

$$
\begin{array}{r}
\frac{W_{i-1}-2 W_{i}+W_{i+1}}{(\Delta X)^{2}}+\frac{\alpha W_{i}}{\left(1+W_{i}\right)} \\
\left(\beta\left(\frac{W_{i-1}+W_{i+1}}{2 \Delta X}\right)-1\right)=0
\end{array}
$$

For the displacement, $W_{i}$, at node i, equivalent form is $\quad W_{i-1}+W_{i+1}-2 W_{i}+\frac{\alpha C_{1} / n^{2} W_{i}}{\left(1+W_{i}\right)}=0$

by letting, $C_{1}=\left\{\beta n \frac{\left(W_{i+1}-W_{i-1}\right)}{2}-1\right\}$

Thus, we get for $i^{\text {th }}$ node as,

$$
W_{i}=\frac{W_{i-1}+W_{i+1}}{\left(2-\alpha \frac{C_{1}}{n^{2}\left(1+W_{i}\right)}\right)}
$$




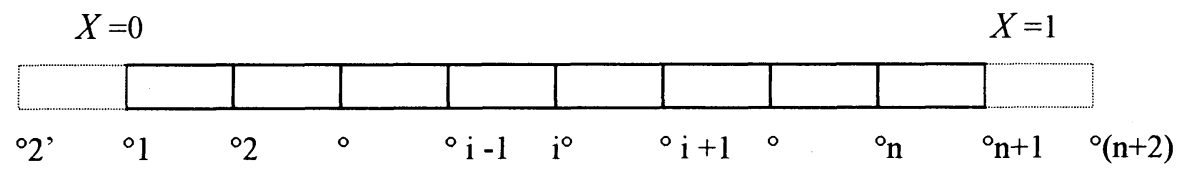

Fig. 3 Discretisation elements for reinforcement

To solve for displacements at nodes 1 and $n+1$, two fictitious nodes, 2' to the left of node ' 1 ' and $(n+2)$ to the right of node $(n+1)$ are assumed. The displacements at these nodes can easily be derived from the boundary conditions (Eq.s, 10 and 11) redefined as follows

$$
W_{2}^{\prime}=W_{2}+2 \alpha T / n
$$

and

$$
W_{n}=W_{n+2}
$$

Knowing $W_{2}^{\prime}$ and $W_{n+2}$, the normalised displacements at nodes 1 and $(n+1)$ are once again obtained from Eq. (13). From the known displacements along the reinforcement length, strain, $\varepsilon_{i}$ and normalised pullout force, $T_{i}$, at node $\mathrm{i}$, are obtained as

and

$$
\varepsilon_{i}=n \frac{\left(W_{i-1}-W_{i+1}\right)}{2}
$$

$$
\text { and } \quad T_{i}=n \frac{\left(W_{i-1}-W_{i+1}\right)}{2 \alpha}
$$

\section{RESULTS AND DISCUSSION}

The solution for the normalised displacements, strains and normalised pullout forces along the reinforcement length are obtained by solving Eq.S (13) through (17) numerically. The accuracy of the solution is checked by varying ' $n$ ', the number of elements into which the reinforcement is discretised. The differences in displacements for $n$ equal to 20 and 40 were negligible. Therefore, $n=20$ is adopted for all further calculations. Parametric studies have been carried out for the following ranges of parameters: $T^{*}=0-1.0, \alpha=2$ to 200 and $\beta=$ 0.001 to 0.2 ; where $\alpha\left(=2 k_{s} L^{2} / E_{r} t_{r}\right)$ is a relative stiffness parameter and $\beta\left(=w_{m} / L\right)$ is a relative displacement parameter.

The product $\alpha \beta\left(=T_{m} / E_{r} t_{r}=2 \sigma_{n}^{\prime} \mu L / E_{r} t_{r}\right)$ is a function of the maximum pullout force (a function of the normal stress, the coefficient of interface shear resistance and the length) and the reinforcement stiffness only and is independent of the unit shear

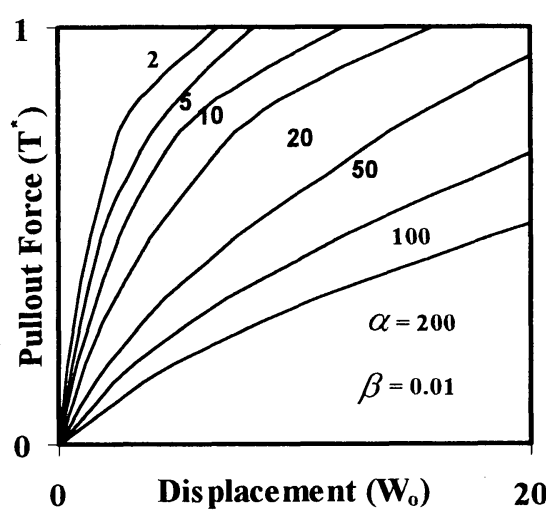

Fig. 4 Displacement vs. pullout force ( $\beta=0.01$ )

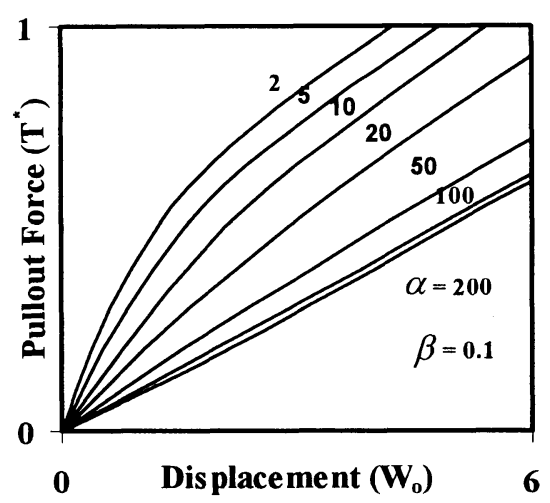

Fig. 5 Displacement vs. pullout force ( $\beta=0.1$ )

stiffness, $k_{s}$. Sobhi and Wu's ${ }^{16)}$ results could be derived theoretically from the above formulation with a finite value of $\alpha \beta$ but with either $\alpha \rightarrow \infty$ or $\beta \rightarrow 0$. The variation of the normalised displacement, $W_{0}$, at the pullout end $(X=0)$ with normalised pullout force, $T^{*}$, is presented in Fig. 4, for $\beta=0.01$ and for different values of relative stiffness parameter, $\alpha=2,5,10,20,50,100$ and 200.

The displacements increase non-linearly with pullout force $T^{*}$. Results similar to those with $\beta=$ 0.1 is shown in Fig. 5 . 


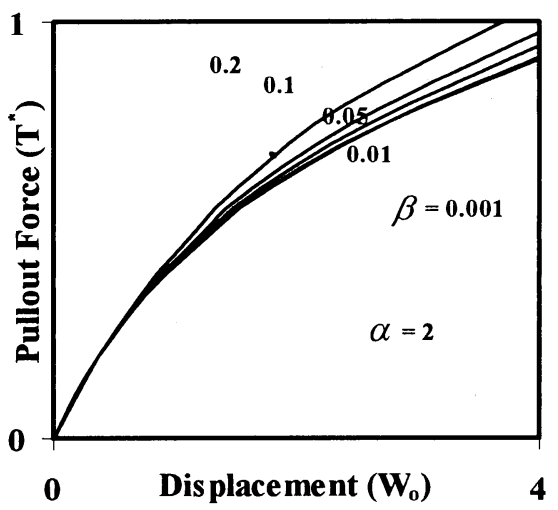

Fig. 6 Displacement vs. pullout force ( $\alpha=2$ )

In this case, the normalised displacements at the pullout end are smaller as $\beta=0.1$ implies a higher maximum shear resistance, $\tau_{m}$. The values of displacements for later cases are lesser. The rate of increase in $W_{0}$ is more at higher pullout forces, as a consequence of the elements near the pullout force end attaining their maximum shear resistance values and slipping without mobilising any additional shear resistance. For a given soil-reinforcement interface, values of $\alpha$ increase either if the length, $L$, of the reinforcement, is larger or if the stiffness, $E_{r}$, of the reinforcement is smaller. In either case, it is justifiable that displacements for all pullout force levels increase with $\alpha$ (because of longer or highly extensible reinforcement).

The influence of the relative displacement parameter $\beta$, on the normalised pullout end displacements versus pullout force response is depicted in Fig. 6 for $\alpha=2$. The $\alpha$ remaining constant and $\beta$ is varying implies that the maximum shear resistance $\tau_{m}$, is varying but the interface shear stiffness $k_{s}$ is constant. Higher the value of $\beta$, higher will be the maximum pullout force $\tau_{m}$ and larger will be the displacement $w_{m}$, for attaining the yield or maximum shear stress.

Consequently, the curves for higher values of $\beta$ exhibit relatively smaller pullout end displacements at the given pullout force level. For example at $T^{*}=$ $0.4(\alpha=2)$, the displacements are $0.84,0.88,0.90$, 0.92 and 0.92 for $\beta$ values of $0.001,0.01,0.05,0.1$ and 0.2 respectively. These differences increase with increasing values of pullout force. The results are not affected by any $\beta$ for the $\beta$ values $\leq 0.0001$.

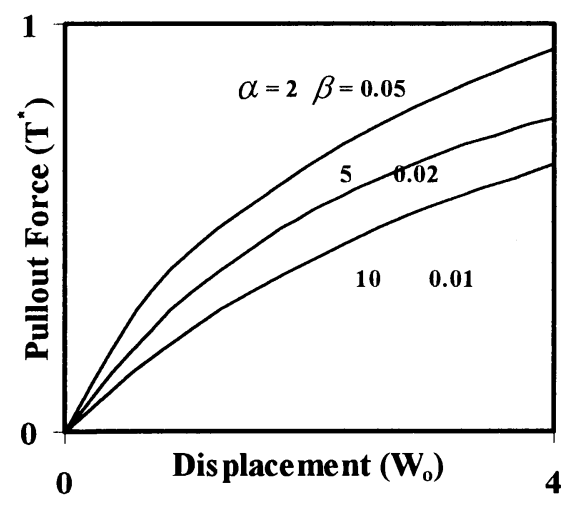

Fig. 7 Displacement vs. pullout force ( $\alpha \beta=0.1$ )

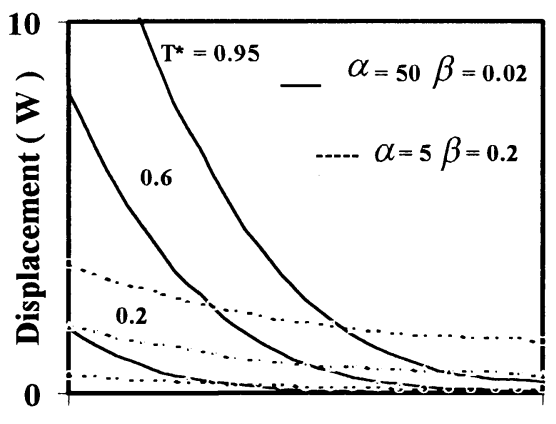

0 Normalised Dis tance ( $X$ ) 1

Fig. 8 Displacement vs. distance $(\alpha \beta=1)$

The product $\alpha \beta=0.1$ remaining constant, the displacement responses at various pullout forces for different combinations of $\alpha_{1}=10, \beta_{1}=0.01$, $\alpha_{2}=5, \beta_{2}=0.02, \alpha_{3}=2, \beta_{3}=0.05$ are shown in Fig. 7. Remarkable decrease of displacements at any given level of pullout force can be noted with decreasing $\alpha$ values. The displacements are very sensitive to the input values of $\beta$. Low values of $\beta$ $\left(=w_{m} / L=\tau_{m} / k_{s} L\right)$ imply small unit shear resistance, very long reinforcement or very stiff interface response (higher $k_{s}$ ). Thus the response curves are highly non-linear for low values of $\beta$ (low shear stress, long reinforcement or very high interface stiffness). Thus Fig. 7 brings out the importance of considering both the stiffness and the maximum shear stress of the interface. The value of displacement reduces relatively for the reduced values of $\alpha$. Also, higher $\beta$ indicates increased stiffness of the interactive media. 


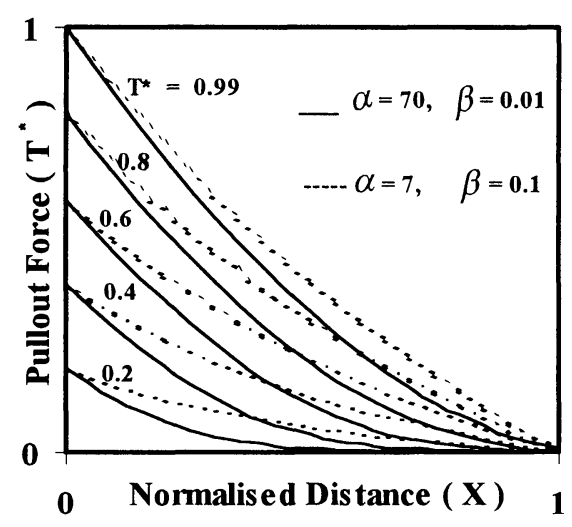

Fig. 9 Pullout force vs. distance ( $\alpha \beta=0.7$ )

The variation of displacement with distance along the length of the reinforcement for various pullout force level $\left(T^{*}=0.95,0.6 \& 0.2\right)$ is shown in Fig. 8 for a constant value of the product $\alpha \beta=1$ but with $\alpha=50, \beta=0.02$ and $\alpha=5, \beta=0.2$. The displacements reduce rapidly with distance for higher value of $\alpha$ and lower value of $\beta$ implying that only a part of the reinforcement actively mobilises the pullout resistance. In contrast, if $\alpha$ is smaller or $\beta$ is larger, the full length of the reinforcement participates in mobilising resistance to pullout. These results also emphasise the need to consider the stiffness parameter, $k_{s}$.

The effect of interaction parameters can be studied by considering various $\alpha$ and $\beta$ combinations for the pullout force displacement responses. Curves given for two pairs of $\alpha$ and $\beta$ ( $\alpha=7, \beta=0.1$ and $\alpha=70, \beta=0.01$ ) but with the same product value of 0.7 , demonstrate the effect of $k_{s}$ or $\alpha$ on the pullout interactions. Stiffer the reinforcement, shorter would be the effective resistive length of reinforcement at all stress levels. From the pullout force-distance relations; refer Fig. 9, the extended length of the reinforcement can be found out under a given applied pullout force.

For any given interface bond strength $\left(\tau_{m}\right)$ and reinforcement characteristics $\left(E_{r}, t_{r} \& L\right)$, the product $\alpha \beta$ is unique. However, it can be concluded that the interface shear stiffness $k_{s}$, has significant influence on the pullout response for highly extensible reinforcement. The displacement-pullout curves are highly non-linear particularly for higher values of the relative stiffness parameter $\alpha$.

\section{VERIFICATION OF THE MODEL}

Field and laboratory pullout tests are used to illustrate estimation and evaluation of the interface interaction parameters between reinforcement and soil. The numerical predictions are compared with results of laboratory and field pullout tests on geotextiles and nylon as well as on polymer strip geosynthetics. The various interface interaction parameters for the field and laboratory pullout experiments may be estimated from the pre-failure pullout test. For any given overburden pressure, $\sigma_{n}{ }^{\prime}$, the interface shear stress $\tau_{m}=\sigma_{n}^{\prime} \mu$ and then total pullout resistance $T_{m}=2 \tau_{\mathrm{m}} L$ per unit width can be estimated. The product of interaction parameters can be evaluated by $\alpha \beta=T_{m} / E_{r} t_{r}$. An approximate estimation of the first hand $\alpha$ parameter may be made from a pullout data (at relatively small force range) by

$$
\frac{w}{T}=\frac{L}{\sqrt{\alpha} E_{r} t_{r} \tanh (\sqrt{\alpha})}
$$

Equation (18) expresses the initial slope of the displacement versus pullout force in terms of the reinforcement characteristics, $E_{r}, t_{r}$ and $L$, and the interface shear stiffness, $k_{\mathrm{s} .}$ Derivation details can be obtained from Madhav et al. ${ }^{9}$. . Eq. (18) may be used to estimate the value of $\alpha$ from the initial slope of the force-displacement curve of the pullout test. For an estimated value of $\alpha$, the corresponding $\beta$ value can be obtained and few check combinations of these $(\alpha, \beta)$ may be used to compare the numerical simulation with test results by fitting the pullout response curve. For known values of $E_{r}, t_{r}$ and $L$, the value of $k_{\mathrm{s}}$ may be estimated from the initial slope of displacement-pull-out force curve.

Field pullout tests on polymer strip geosynthetic reinforcements were reported by Konami et al. ${ }^{8)}$. The pullout tests were conducted at various depths in a fill densified to a unit weight of $18.6 \mathrm{kN} / \mathrm{m}^{3}$ at dry condition. The length of the reinforcements was 3.5 $\mathrm{m}$. The manufacturer's reported material properties for $E_{r} t_{r}$ was $34.3,53.9 \mathrm{kN} / \mathrm{cm}$ at $2 \%$ and $23,39.2$ $\mathrm{kN} / \mathrm{cm}$ at $5 \%$ strains for PW-3 and PW-5 type geosynthetics respectively. But Konami et al. ${ }^{8)}$ estimated the actual effective rigidities $\left(E_{r} t_{r}\right)$ as 38.8 and $59.7 \mathrm{kN} / \mathrm{cm}$ for $\mathrm{PW}-3$ and $\mathrm{PW}-5$ respectively from the linear slope of the pullout (test in soil) result plots. The later report is more realistic and is adopted in the analysis. Typical normal stresses can be computed as 89.3, 59.5, 29.8 and 
Interface Pullout Friction in various

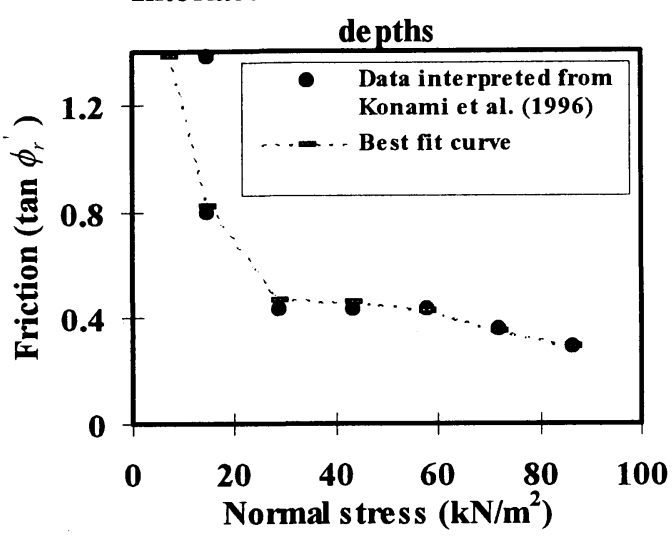

Fig. 10 Interface friction vs. normal stress

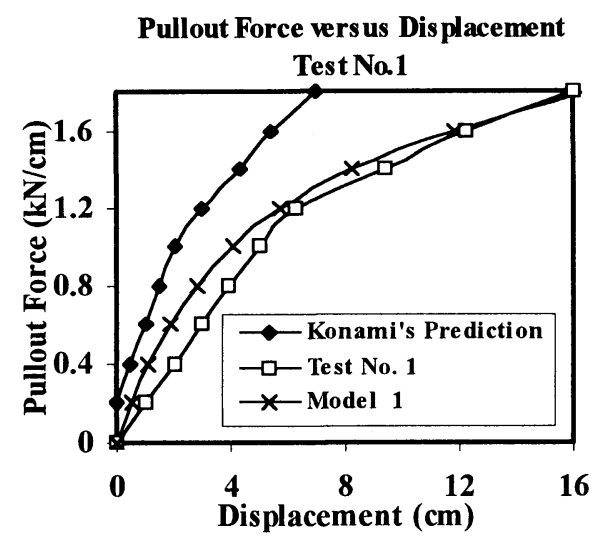

Fig.11 Pullout force vs. displacement for test no.1

$14.9 \mathrm{kN} / \mathrm{m}^{2}$ for tests at various depths of $4.8,3.2$, 1.6 and $0.8 \mathrm{~m}$ respectively. The mobilised shear stresses may be estimated as 26.8, 26.2, 13.7 and $20.5 \mathrm{kN} / \mathrm{m}^{2}$ for the friction coefficient of $0.3,0.44$, 0.46 and 1.38 (Fig. 10) respectively. The interface friction angle, $\phi_{r}$ between the fill and the reinforcement was $38.2{ }^{\circ}$ from the direct shear tests. But the maximum pullout stress cannot exceed the mobilised limiting interface shear strength or the tensile breaking strength of the material.

From the published data, using variation concept of mobilised friction with mean stress levels (Jewell $\&$ Wroth ${ }^{7)}$ ) or depth (Bolton \& Powerie ${ }^{3)}$ ), the value of mobilised friction versus normal stress was plotted in Fig. 10. The breakage of reinforcement due to tensile stress occurred approximately at $14 \%$ elongation while $5 \%$ elongation takes place only under nearly $50 \%$ load of the normal strength.
Pullout Force vers us Displacement

Test No. 2

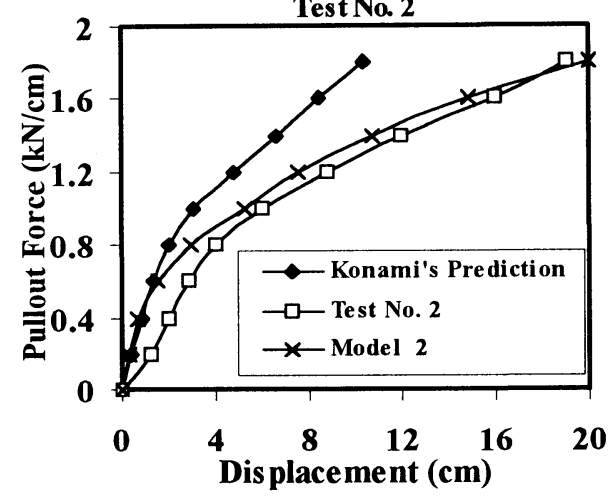

Fig.12 Pullout force vs. displacement for test no.2

From the available data, the normal stress $\sigma_{n}{ }^{\prime}$, shear stress $\tau_{m}=\sigma_{n}^{\prime} \tan \phi_{r}^{\prime}$ and maximum pullout force $T_{m}=2 \tau_{m} L$ per unit width for various depths were calculated and summarised in Table 1 . Knowing the effective reinforcement rigidity $E_{r} t_{r}$, the product $\alpha \beta=T_{m} / E_{r} t_{r}$ are estimated as 0.0314 , $0.0307,0.0247$, and 0.0370 for tests nos. $1,2,3$, and 4 respectively. The interaction product, $\alpha \beta$ $=T_{m} / E_{r} t_{r}$ is a real entity of pullout test and so is the relative stiffness parameter, $\alpha\left(=2 k_{s} L^{2} / E_{r} t_{r}\right)$ that expresses the ratio of soil and reinforcement material stiffnessess. Accuracy on estimation of these parameters is very important as it affects the prediction of the relative displacement parameter, $\beta$ $\left(=w_{m} / L\right)$ which is like strain expressed in nondimension of ratio instead of percent and needs to quantify in fourth order of decimal figures at least.

As the values of the interface stiffness, $k_{s}$, were not directly available from the test data, the estimation was made by using Eq. (18). Estimating the value of $\alpha$, and also knowing the product ( $\alpha \beta$ ), the value of $\beta$ can be easily calculated. The test parameters, values of estimated $\alpha, \beta$ and $k_{s}$, are summarised in Table 1 . In all the cases, the displacements with $\alpha$ and $\beta$ based on initial tangent value of $k_{s}$ at all pullout forces slightly over-predicted while those based on appropriate choice of $\alpha$ and $\beta$ values appear to fit closely with the experimental results. 
Pullout Force versus Dis placement Test No. 3

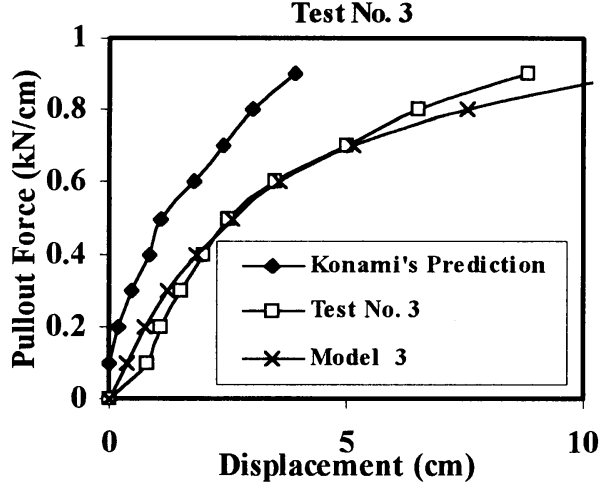

Fig. 13 Pullout force vs. displacement for test no. 3

Pullout Force versus Displacement Test No. 4

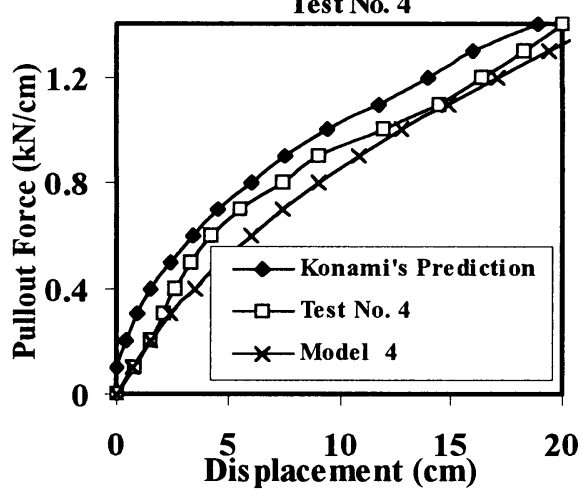

Fig.14 Pullout force vs. displacement for test No. 4

The experimental results with the predictions from (i) Konami et al. ${ }^{8)}$ based on a simple elastic approach which assumes full mobilisation of full shear resistance over an effective length, and (ii) the present hyperbolic approach are compared for illustrations (Fig.'s 11-14). The hyperbolic model is valid for cases of planar reinforcements only.

Pullout results from tests on $300 \mathrm{~mm}$ long geotextile (Sobhi and $\mathrm{Wu}^{16)}$ ) are compared with the method proposed herein Fig. 15. Sobhi and $\mathrm{Wu}^{16)}$ obtained closed form solutions for pullout force assuming full shear resistance mobilisation and rigid plastic type of response. For normal stress of 40 $\mathrm{kPa}$, the maximum pullout force was $6.9 \mathrm{kN} / \mathrm{m}$ taking the reported value of friction, $\mu$ equal to 0.29 . With geotextile stiffness $E_{r} t_{r}=32 \mathrm{kN} / \mathrm{m}$, the product $\alpha \beta$ was estimated to be 0.2175 . Table 1 summarises the given and estimated parameters.
Pullout Force versus Displacement

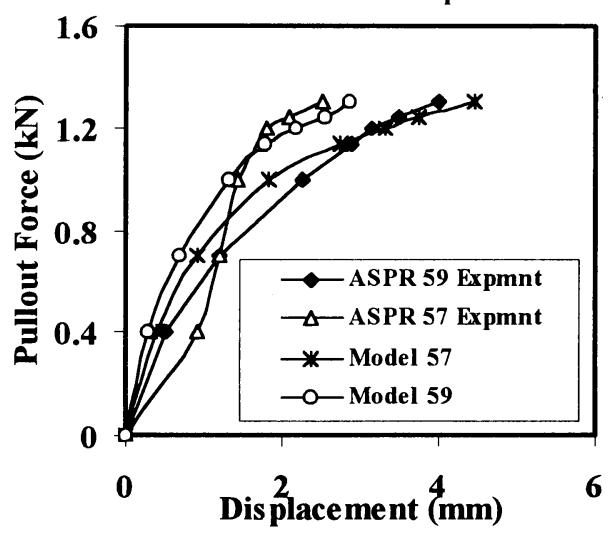

Fig.15 Pullout force vs. displacement at $\mathrm{x}=0$ end

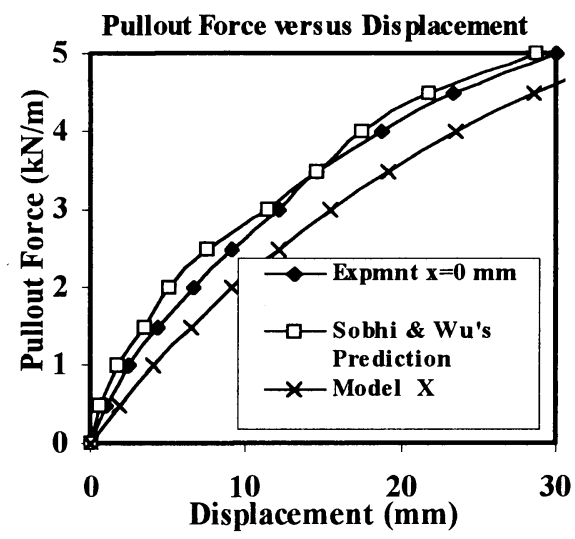

Fig.16 Pullout force vs. displacement for ASPR 57/59

The predictions by this method proposed with $\alpha=9, \quad \beta=0.0242$ are compared with the experimental values.

Lastly, pullout tests on Nylon 6/6 Inclusion ASPR 57 and ASPR 59 (Abramento and Whittle ${ }^{2)}$ ) were analysed using the proposed model. The length, width and thickness of inclusion were $42 \mathrm{~cm}, 13.34$ $\mathrm{cm}$ and $0.598 \mathrm{~mm}$ respectively. The tests were conducted at a confining pressure $\sigma_{n}{ }^{\prime}$ of $24.5 \mathrm{kPa}$ but at displacement rates of 35 and $3.5 \mu \mathrm{m} / \mathrm{s}$.

The estimated value of $T_{m}=2 L \sigma_{n}{ }^{\prime} \tan \phi^{\prime}{ }_{r}=8.4$ $\mathrm{kN} / \mathrm{m}$ gave the interaction product, $\alpha \beta=T_{m} / E_{r} t_{r}$. as 0.0087 as the interface friction angle of sand was $20-25^{\circ}$. The laboratory results for tests ASPR 57 and ASPR 59, are plotted and compared with the 
Table 1 Summary of pullout test parameters

\begin{tabular}{|c|r|c|c|c|c|r|r|r|r|r|r|}
\hline $\begin{array}{c}\text { Name of } \\
\text { Experiments }\end{array}$ & Test & Depth & $\sigma_{n}^{\prime}$ & $\mu$ & $L$ & $E_{r} t_{r}$ & $\begin{array}{c}T_{m} \\
=2 L \mu \sigma_{n}\end{array}$ & $\begin{array}{c}\alpha \beta \\
=T_{m} / E_{r} t_{r}\end{array}$ & $\alpha$ & $\beta$ & $k_{s}$ \\
\hline Unit & & $\mathrm{m}$ & $\mathrm{kPa}$ & & $\mathrm{m}$ & $\mathrm{kN} / \mathrm{m}$ & $\mathrm{kN} / \mathrm{m}$ & & & & $\mathrm{kN} / \mathrm{m}^{3}$ \\
\hline Konami et al. $^{8)}$ & 1 & 4.8 & 89.3 & 0.30 & 3.50 & 5970 & 187.5 & 0.0314 & 6 & 0.0052 & 1460 \\
\cline { 2 - 13 } & 2 & 3.2 & 59.5 & 0.44 & 3.50 & 5970 & 183.3 & 0.0307 & 4 & 0.0077 & 975 \\
\cline { 2 - 12 } & 3 & 1.6 & 29.8 & 0.46 & 3.50 & 3880 & 95.8 & 0.0247 & 9 & 0.0027 & 1425 \\
\cline { 2 - 12 } & 4 & 0.8 & 14.9 & 1.38 & 3.50 & 3880 & 143.7 & 0.0370 & 1 & 0.0370 & 160 \\
\hline Sobhi \& Wu $^{16)}$ & $\mathrm{x}=0$ & & 40.0 & 0.29 & 0.30 & 32 & 6.9 & 0.2175 & 9 & 0.0242 & 1600 \\
\hline $\begin{array}{c}\text { Abramento \& } \\
\text { Whittle }^{2)}\end{array}$ & 57 & & 24.5 & 0.41 & 0.42 & 975 & 8.4 & 0.0087 & 15 & 0.0006 & 41450 \\
\cline { 2 - 11 } & 59 & & 24.5 & 0.41 & 0.42 & 975 & 8.4 & 0.0087 & 50 & 0.0002 & 138180 \\
\hline
\end{tabular}

numerical responses of the model for $\alpha=15, \beta=$ 0.0006 and $\alpha=50, \beta=0.0002$ combinations. It satisfactorily simulated the pullout test results of Abramento and Whittle ${ }^{2)}$ as shown in Fig. 16.

Table 1 presents the summary on test details, estimated interaction parameters and the backcalculated interface shear stiffness. The effect of depth or the normal stress on the mobilised shear stress and finally on the interface shear stiffness parameter can be observed in tests results of Konami et al. ${ }^{8}$. For example, the test 4 shows relatively lower value of $k_{s}$ in some proportion with its test depth assuming same type of polymer. The relation is little bit complex due to other soil material parameters and repeatability of the tests. Similarly, the effect of material stiffness $E_{r} t_{r}$ on the generated interface shear stiffness may be deduced from the pullout test results of Sobhi and $\mathrm{Wu}{ }^{16)}$ with Abramento and whittle ${ }^{2)}$. The value and order of $E_{r} t_{r}$ directly affects the interactions parameters ( $\alpha$ and even $\beta$ ) and thus the order of the $k_{s}$. Numerical simulation is possible if accurate pullout test details on soil and planar reinforcements are available.

\section{CONCLUSIONS}

A new hyperbolic model for highly extensible reinforcement in the pullout test has been developed.

The boundary interface was solved to get resulting non-linear governing equation, which was nondimensionalised for numerical parametric analysis. The expressed equation in finite difference form was solved by the Guass-Siedel iteration method. Varying the number of elements checked the accuracy as well as efficiency of the numerical solution. The result showed that discretisation of reinforcement length into twenty elements give accurate values in very efficient computer time. Two new soil-inclusion interaction terms, the relative stiffness parameter $\alpha$ and the relative displacement parameter $\beta$ were conceptualised and it was expressed in nondimensional form for wide general application.

A hyperbolic form of mobilisation of interface stresses with displacement was taken into consideration. Normalised pullout force versus displacement responses are presented for various ranges of relative stiffness parameters $\alpha$ and $\beta$. Comparison of predicted displacements with those from reported experiment show satisfactory agreement. Results of field pullout tests (Konami et al. ${ }^{8)}$ ) on polymer strips, lab pullout tests on geotextile (Sobhi and $\mathrm{Wu}{ }^{16)}$ ) and nylon 6/6 inclusion (ASPR 57/59 - Abramento and Whittle ${ }^{2)}$ ) were compared. The effect of depth or normal stress of tests and mobilised shear resistances as well as the effect of material stiffness, length and thickness etc. can be studied to explain the effect on mobilised interaction parameters and interface shear stiffness values. The present model demonstrates good predictions in general. Better estimation of soilreinforcement interaction parameters (such as $\tau, \mu$, $k_{s}, \alpha$ and $\beta$ ) directly from the test details could even improve the predictability of the test results.

ACKNOWLEDGEMENT: The first author would like to express his sincere gratitude to Professor M.R. Madhav of the Indian Institute of Technology, Kanpur, India and deep respects to Chair Professor A.S. Balasubramaniam and Professor D.T. Bergado of the Asian Institute of Technology, Bangkok, Thailand for their invaluable academic enlightenment. 


\section{REFERENCES}

1) Abramento, M. and Whittle, J. A.: Analysis of Pullout Tests for Planar Reinforcements in Soil, Journal of Geotechnical Engineering, ASCE, Vol. 121, No. 6, pp. 476-485, 1995.

2) Abramento, M. and Whittle, J. A.: Experimental Evaluation of Pullout Analyses for Planar Reinforcements, Journal of Geotechnical Engineering, ASCE, Vol. 121, No. 6, pp. 486-492, 1995.

3) Bolton, M. D., and Powerie, W.: Behaviour of Diaphragm Walls in Clay prior to Collapse, Geotechnique, Vol. 38, No. 2, pp.167-189, 1988.

4) Christopher, B.R., Gill, S.A., Giroud, J.P., Juran, I., Mitchell, J. K., Schlosser, F. and Dunnicliff, J.: Reinforced Soil Structures, Vol. I, Design and Construction Guidelines, Federal Highway Administration Report No. FHWA-RD-89-043, Washington, D. C., USA, 1990.

5) Gurung, N. and Iwao, Y.: Pull-out test analysis for georeinforcements, Geotextiles and Geomembranes, IGS, Elsevier Science, Vol. 17, 1999 (in press)

6) Hausmann, M. R.: Strength of Reinforced Soil, Proc. $8^{\text {th }}$ Australian Road Research Conference, Vol. 8, Sec. 13, pp. 1-8, 1976.

7) Jewell, R. A., and Wroth, C. P.: Direct Shear Tests on Reinforced Sand, Geotechnique, Vol. 37, No. 1, pp. 53-68, 1987.

8) Konami, T., Imaizumi, S. and Takahashi, S.: Elastic Considerations of Field Pull-out Tests of Polymer Strip, Proc. of The International Symposium on Earth Reinforcement, Kyushu, Japan, ISBN 905410833 9, pp. 57-62, 1996.

9) Madhav, M.R., Gurung N. and Iwao Y.: A Theoretical Model for Pull-out Response of Extensible Reinforcements, Geosynthetics International, Vol. 5, No. 4, pp. 399-424, 1998.
10) McGown, A., Andrawes, K. Z. and Al-Hasani, M. M. : Effect of Inclusion properties on the Behaviour of Sand, Geotechnique, Vol. 28, No. 3, pp.327-346, 1978.

11) Mitchell, J.K. and Villet, W.C.B.: Reinforcement of Slopes and Embankments, National Co-operative Highway research Program report No. 290, Transportation Research Board, national Research Council, Washington, D. C., USA, 323 p, 1987.

12) Pradhan, T. B. S., Shiwakoti, D.R. and Imai, G.: Effect of Normal Pressure and Width of Geosynthetic Horizontal Drain in Pullout Behaviour using Saturated Clay, Proc. of The International Symposium on Earth Reinforcement, Kyushu, Japan, ISBN 905410833 9, pp. 133-138, 1996.

13) Schlosser, F. and Long, N.T.: Recent results in French Research on Reinforced Soil, Journal of Construction Engineering, ASCE, Vol. 100, No.3, pp. 223-237, 1973.

14) Schlosser, F. and de Buhan, P.: Theory and Design Related to the Performance of Reinforced Soil Walls, Proc. Int'l Reinforced Soil Conference, Glasgow, pp. 1-14, 1990.

15) Segrestin, P. and Bastick, M.: Comparative study and measurement of the Pullout Capacity of extensible and In extensible Reinforcements, Proc. of The International Symposium on Earth Reinforcement, Kyushu, Japan, ISBN 905410833 9, pp. 139-144, 1996.

16) Sobhi, S. and Wu, J.T.H.: Interface Pullout Formula for Extensible Sheet Reinforcement, Geosynthetics International, Vol.3, No.5, pp. 565-581, 1996.

17) Yang, Z.Z.: Strength and Deformation Characterstics of Reinforced Sand, $\mathrm{PhD}$ Thesis, University of California, Los Angeles, USA, 1972.

(Received June 4, 1998)

\title{
補強土の引き抜きモデルを用いた伸張解析
}

\author{
ネトラ グルング・岩尾 雄四郎
}

新しい引き抜きモデルは, 補強土の伸張に関する解析手法として提案されている. 引き抜きのメカ二 ズムを表す非線形式は，無次元で形状の異なる要素として扱われ，Guass-Siedel手法を用いて算出され . また, 本手法の適応性は, その剛性や結合抵抗の広い範囲で認められてきた.本論文は, 荷重之変位 の関係, 引き抜き力の種類, 及び距離に伴う変位について論じる. また, 本モテルの解析結果を济オテ キスタイル, ポリマー及びナイロンの補強材を用いた実験結果によって検証する. 